\title{
PROGRESSIVE COLLAPSE MECHANISM OF STEEL FRAMED-STRUCTURES SUBJECTED TO A MIDDLE-COLUMN LOSS
}

\author{
Wen-Jin Zhang ${ }^{1}$, Guo-Qiang Li ${ }^{1,2}$ and Jing-Zhou Zhang 1,* \\ ${ }^{1}$ College of Civil Engineering, Tongji University, 1239 Siping Road, Shanghai 200092, China \\ ${ }^{2}$ State Key Laboratory for Disaster Reduction in Civil Engineering, Tongji University, 1239 Siping Road, Shanghai 200092, China \\ *(Corresponding author: E-mail: jzzhang1992@163.com)
}

\section{A B S T RA C T}

This paper analytically deals with the collapse resistance of steel framed-structures due to a middle column loss. The fourstage resistance-displacement relationships are proposed for both the bare steel frame and the braced steel frame. The reliability of the analytical method is verified against numerical analyses. Parametric studies are conducted to investigate the effects of frame height, span and stiffness ratio of beam to column on the collapse resistance of the frame. It is concluded that the yielding capacity, ultimate capacity, post-yielding stiffness and ultimate displacement of the steel frames can be reasonably predicted by the analytical method with acceptable errors. It is found that a greater number of storeys, shorter span of beams and larger beam to column stiffness ratio ensure better performances of the frame against collapse. Moreover, even though the bracing system can enhance the lateral stiffness of the main steel frame with certain extents, it reduces the collapse resistance and failure displacement of the frame because the column at the base-storey prematurely loses its stability.
A R T I C LE H I S T ORY

$\begin{array}{ll}\text { Received: } & \text { 25 December } 2020 \\ \text { Revised: } & \text { 5 May 2021 } \\ \text { Accepted: } & 7 \text { May } 2021\end{array}$

\section{K E Y W O R D S}

Progressive collapse;

Steel braced frame;

Middle column loss;

Catenary action;

Plastic hinge

\section{Introduction}

The term "progressive collapse" refers to the phenomenon where the structure disproportionally or completely collapses even due to the limited local failures of certain load-bearing members. In 1976, measurements on enhancing the structural robustness against collapse were first proposed in British Building Regulations [1] after the catastrophic collapse of Ronan Point Tower [2]. Afterwards, collapses of Alfred P. Murrah building [3] and World Trade Center Towers [4] in USA further facilitated developments of safety design of structures [5-7]. Two methods are proposed in building regulations to enhance the robustness of structures in the event of column losses, namely, indirect and direct methods. For the indirect methods, constructive measures (e.g. ductility detail and system redundancy) are required to ensure sufficient connectivity among structural components [5]. For the direct methods, the robustness of structures to resist progressive collapse is explicitly assessed [7]. In the Alternate Path Method, as a common direct approach, different columns, especially those at corner or along the edge of the building, are removed to investigate the resistance of the remaining structure to guarantee alternative load transferring paths.

Steel framed-structures are widely used in various buildings due to their high constructional efficiency and excellent seismic performance [8]. Research on progressive collapse resistance of steel framed-structures has been successively launched in the last decades [9-17]. Li et al. [11] tested three twostorey four-span planar steel frames in a case of a sudden middle column loss. A three-hinged column and steel hammer system was specially design to achieve a sudden column loss scenario. The dynamic effects on the structural behavior, final deformation modes and load redistributing path of the frame after the column-removal stage were studied. Jiang et al. [13] investigated the structural behaviors of planar steel frames under a localized fire scenario with extensive numerical analyses. Three typical collapse modes were found, namely failure of high load ratio member, tensile force-induced failure and cantilever beam failure. Jiang et al. [16] studied the dynamic responses of steel columns with rotational and axial restraints under a fire scenario. The results of parametric analyses by varying axial and rotational stiffness, column slenderness and load ratio showed that typical dynamic responses of the frame occurred even in a static fire scenario, especially when the axial and rotational restraints of the column were small and the load ratio was large. The above mentioned research mainly focused on the bare steel frame, in real circumstances, however, steel bracing systems are always employed to enhance the lateral stiffness and therefore increase the redundancies of the frame in the event of collapse. The reasonability and reliability of applying the conclusions drawn from bare steel frame to steel frame with bracing systems remain to be verified.

The collapse mechanisms of steel frames with bracing systems have been studied by many researchers [18-26]. Jiang et al.[18] numerically investigated the robustness of steel frames with vertical and hat bracing systems. It was found that hat bracing system enhances the collapse resistance of the frame by more reasonably redistributing the gravity loads in columns. However, the vertical bracing system arranging at edge bays has a negative effect on the collapse resistance of the frame due to its negative contribution to spread local damages to global collapse. Talebi et al. [21] studied the effects of buckling restrained bracing systems (BRBs) on the global performances of the steel frame under a fire scenario. It was suggested that BRBs provided a greater collapse time to the frame due to an induced larger stiffness. Compared with other bracing systems, the BRBs more efficiently maintain the stability of the frame after the sudden column removal scenario. Asgarian and Rezvani [24] proposed an Extend Progressive Collapse Analysis (EPCA) algorithm to evaluate the robustness of steel frames with concentrically bracing systems. The failure mode, minimum residual capacity and the most devastating column loss scenario of the frame can be obtained with the aid of EPCA. Chen et al. [26] studied the contribution of hat bracing system to the resistance of a steel frame under several sudden column loss scenarios. The numerical dynamic analyses indicated that hat bracing system reduces the vertical displacement at the column-removal location by up to $90 \%$.

In the above literatures, the effects of bracing systems on the steel frame in the collapse event are mainly considered by numerical analyses. The EPCA method indeed gave a comprehensive algorithm to evaluate the robustness of steel structures, however, it still needs huge numerical analyses. The essential aim of research on collapse evaluation is to facilitate practical safety design of structures. Analytical method with simple calculations are therefore more necessary. However, such analytical studies focusing on the collapse resistance of steel frame with bracing systems are rare in the literature.

Accordingly, this paper analytically deals with the collapse resistance of steel framed-structures due to a middle column loss. A four-stage resistancedisplacement relationship is proposed for the steel frame with and without bracing systems. The reliability of the analytical method is verified against numerical analyses. Parametric studies are further launched to investigate the effects of frame height, span and stiffness ratio of beam to column on the collapse resistance of the frame. The differences of the collapse mechanisms of the bare and braced frames are also elaborated.

\section{Collapse process of bare and braced frames}

When the middle column at the base-storey of the frame fails due to explosion, impact or even fire actions, the gravity loads initially suffered by the middle column are bridged over by the steel beams to the adjacent columns of the frame. At small deflections, the bending action in steel beams is the main mechanism to resist loads, while at large deflections, the catenary action enhances the resistance of the beam with great extent. Fig. 1 (a) and Fig. 1 (b) indicate the middle-column-removal scenario for the bare and braced steel 
frames, respectively. It should be noted that only two spans of the bare frame are considered. This is due to the following reasons. First, even though the frame has more than two spans in real cases, it is conservative to ignore the restraints from those spans. Second, because only two spans of frames are considered in the braced frame, to achieve a fair comparison on the collapse resistance of the two types of frames, only two spans of the bare frame are considered. Actually, for bare frames with more than two spans, the restraints from other spans can be considered into the spring elements at the beam ends and the analytical method proposed is still applicable. Moreover, the spans of the beams at the two sides of the removed column are assumed to be the same. This is because this paper mainly studies the collapse mechanism of the bare and braced steel frame and considering the unequal span of the beams will make the deduction process of the analytical method extremely complicated.

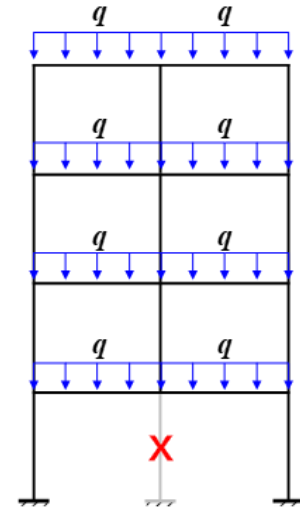

(a) Bare frame structure

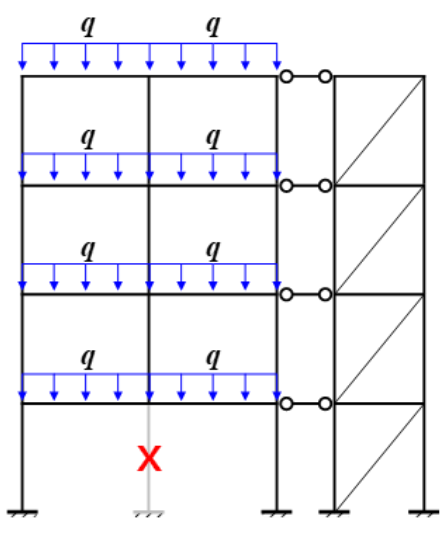

(b) Braced frame structure
Fig. 1 The middle column loss scenario for the bare and braced steel frames

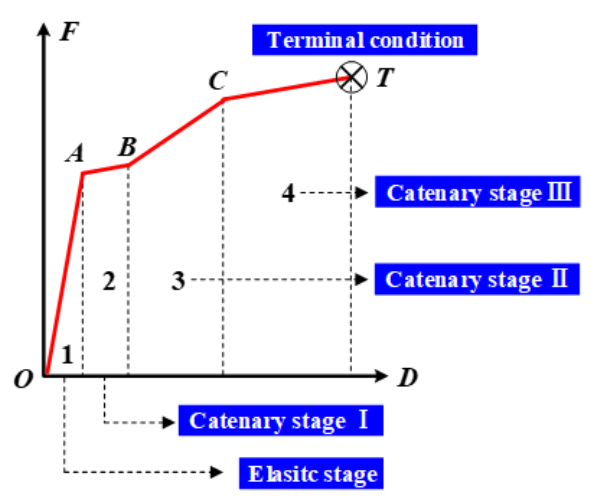

Fig. 2 Resistance-vertical displacement relationship of the steel framed-structures
Fig. 2 shows the simplified resistance-vertical displacement relationship of the frame ( $F-D$ curve) due to a middle column loss. Four stages, namely, elastic stage, catenary stage $I$, catenary stage $I I$ and catenary stage $I I I$ are presented. The structural behavior for the bare and braced frames are the same in elastic stage and catenary stage $I$, while due to the lateral restraints provided by bracing systems, the mechanism of braced frame is different from that of bare frame in catenary stages $I I$ and $I I I$.

In elastic stage $O A$, the frame remains in its elastic status. As shown in Fig. 3 (a), the state when the plastic hinges occur at the bottom beam indicates the end of the elastic stage. Considering that the lateral displacement of the bottom columns is small, the contribution of bracing system to the resistance of steel frames can be ignored. Therefore, it is assumed that the $F$ - $D$ curves in this stage of the frames with and without bracing system are the same.

In catenary stage $I$, as shown in Fig. 3(b) and Fig. 4(a), the plastic hinges at both ends of the bottom beam developed, while the columns remain in elastic state. At this stage, the second-order effect of gravity loads due to geometry nonlinearity on the resistance of the frame starts to be considered. Meanwhile, the gravity loads are partially resisted by the tensile action in steel beams. The lateral displacement of each floor is assumed to be the same with that of the base floor. Therefore, only catenary action in the steel beams at the base floor is considered.

In catenary stage $I I$, with the vertical displacement at the column-removal location increasing, the catenary action in the steel beam will result in a significant inward deflection of the column. Therefore, the plastic hinge will appear at the bottom of the column at the first storey. The deformation configurations for the bare and braced steel frames are presented in Fig. 3 (c) and Fig. 4 (b), respectively. The column tops at the base-storey still remain elastic. For the braced frame, the constraints from bracing systems intensify the lateral displacement at the column top farther from the braces, while the column adjacent to the bracing systems remains in elastic state due to the limited deformation. Therefore, the plastic hinge only occurred at the bottom of column A, as Fig. 4 (b) shows.

In catenary stage $I I I$, plastic hinges at the column top of the base-storey emerged. The final failure modes of the bare and braced steel frames are shown in Fig. 3 (d) and Fig. 4 (c), respectively. At the end of this stage, the frame fails to sustain more loads due to lack of stability considering that the second-order effect due to gravity loads significantly decreases the resistance of the frame. For the braced frame, the column adjacent to the braces still remains in elastic, while most plastic damages concentrate at the column ends on the other side. It is noted that the stability of the frame is determined by the vertical loads and lateral displacement at the column top. Although the bracing system increases the lateral stiffness and optimizes seismic performance of the frame, it fails to guarantee a greater collapse resistance of the frame. This is because the bracing system intensifies the lateral displacement at the column top further from it, leading to a premature failure of the frame. In practical engineering, the ultimate state of the frame may be governed by many conditions, such as shear failures of beam-column connections, tensile fractures of beam ends and beam-column connections. Herein it is determined by the loss of global stability of the column at the base-storey due to the second-order effects of gravity loads.

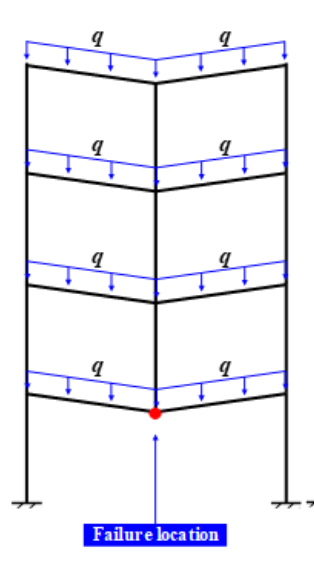

(a) Elastic stage

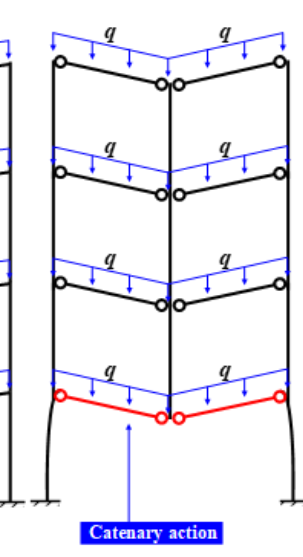

(b) Catenary stage $I$

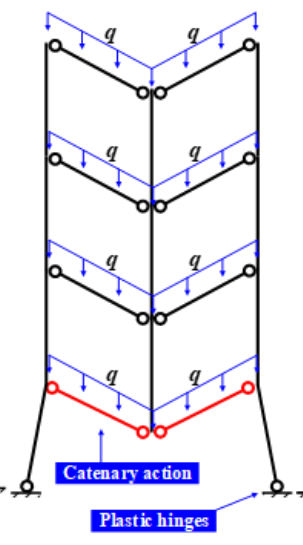

(c) Catenary stage $I I$

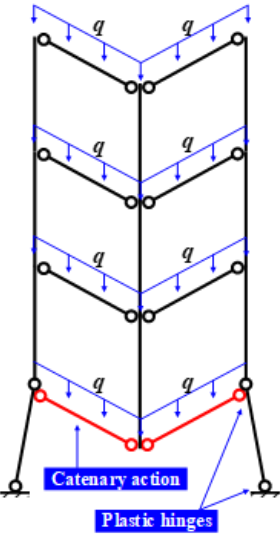

(d) Catenary stage III

Fig. 3 Four stages of symmetric planar frame structure's collapse mechanism 


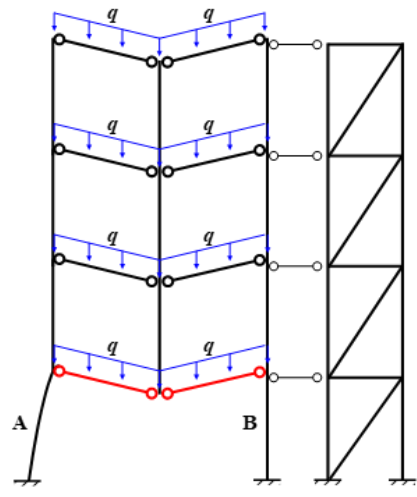

(a) Catenary stage $I$

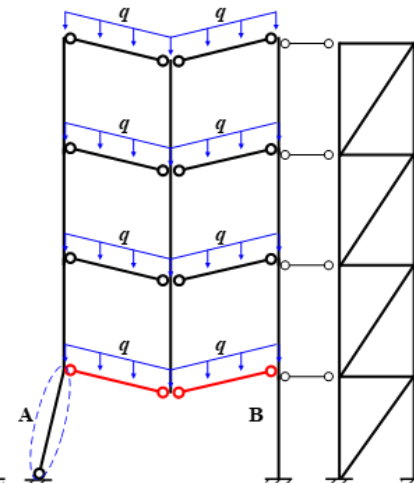

(b) Catenary stage $I I$

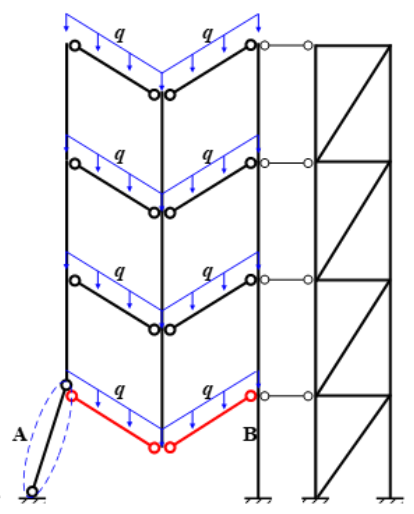

(c) Catenary stage III

Fig. 4 Three catenary stages of planar braced frame structure

\section{Analytical method of collapse resistance for bare steel framed-} structures

\subsection{Elastic stage}

\subsubsection{Elastic stiffness}

Due to the elastic and linear assumption, the total elastic stiffness, denoted as $k_{e}$, can be calculated as the sum of equivalent stiffness provided by frame beams:

$k_{e}=\Sigma k_{b i}$

where $k_{b i}$ is the equivalent vertical stiffness of the frame beam $i$.

Fig. 5 shows the simplified model to determine the equivalent stiffness $k_{b i}$. The rotational restraints provided by the columns are denoted by $k_{d i}$. At the column-removal location, only vertical displacement is allowed and thus the rotation at the beam end can be assumed to be fully restrained. $k_{b i}$ is given as follow:

$$
k_{b i}=\varphi_{b i} \frac{12 i_{b}}{L^{2}}
$$

where $L$ is the span of the steel beam; $i_{b}$ is the linear stiffness of the beam; $\varphi_{b i}$ is the stiffness reduction factor accounting for the partial restraints $k_{d i}$ provided by the columns, which is given by:

$$
\varphi_{b i}=\frac{1-2 \frac{i_{b i}}{k_{d i}}}{1+\frac{i_{b i}}{k_{d i}}}
$$

For regular frames with same height at each storey, the approximate value of $k_{d i}$ for beams at different storeys is given in Table 1

\section{Table 1}

The approximate value of $k_{d}$ for regular structures with uniform story height

\begin{tabular}{cccc}
\hline Number of story & Beam at $2^{\text {nd }}$ story & Beam at normal stories & Beam at top story \\
\hline $\mathrm{N}=1$ & $4 i_{c}$ & $4 i_{c}$ & $4 i_{c}$ \\
$\mathrm{~N}=2$ & $10 i_{c}$ & $10 i_{c}$ & $6 i_{c}$ \\
$\mathrm{~N}>2$ & $10 i_{c}$ & $12 i_{c}$ & $6 i_{c}$ \\
\hline
\end{tabular}

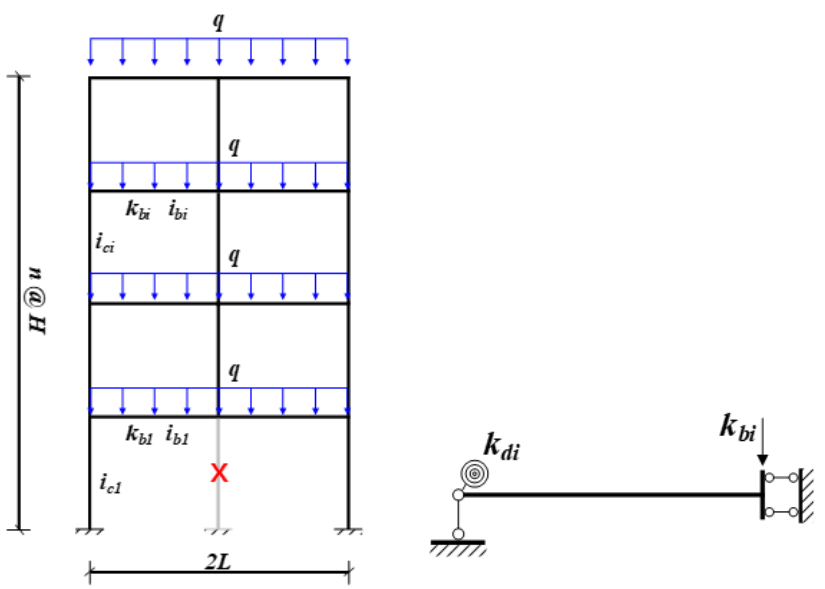

$\begin{array}{ll}\text { (a) Framed-structure due to a middle column loss } & \text { (b) Equivalent beam model }\end{array}$

Fig. 5 The simplified model of equivalent elastic stiffness

\subsubsection{Yielding capacity}

The resistance of the frame at the end of elastic stage is determined by its yielding capacity. Considering that for practical framed-structures, the columns are stronger than beams, the plastic hinges hence emerge at the beam ends near the beam-column connections. The yielding capacity of the frame $F_{y}$ is given by:

$F_{y}=\Sigma F_{b y i}$

where $F_{\text {byi }}$ represents the yielding capacity of each beam, which can be calculated as:

$F_{b y i}=\frac{M_{r, y b i}+M_{l, y b i}}{L_{b i}}$

where $L_{b i}$ is the span of the beam $i, M_{r, y b i}$ and $M_{l, y b i}$ are the plastic moments at the right and left ends of the beam $i$ (shown in Fig. 6), respectively.

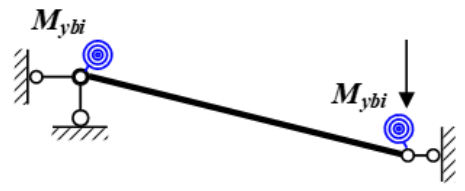

Fig. 6 Plastic hinges at the ends of frame beams 


\subsection{Catenary stage I}

In the catenary stage $I$, the resistance of the frame is calculated by accounting for two contributions, including the bending action (yielding capacity $F_{y}$ ) and the catenary action in steel beams. The enhancement due to catenary action is denoted as $F_{G}$.

\subsubsection{The equivalent link model}

At catenary stage, the horizontal component of the tensile force in steel beams is suffered by the steel columns. To investigate the contribution of catenary action to the resistance of the frame $F_{G}$, an equivalent link model is proposed, as shown in Fig. 7. The frame beams at the base-storey are simplified into links $\mathrm{AB}$ and $\mathrm{BC}$. The restraints due to side columns are simplified into axial springs $\mathrm{DE}$ and $\mathrm{AD}$ with stiffness $k_{e l}$ and $k_{e 2}$, respectively. The effective stiffness of the spring systems $k_{e}$ is given by:

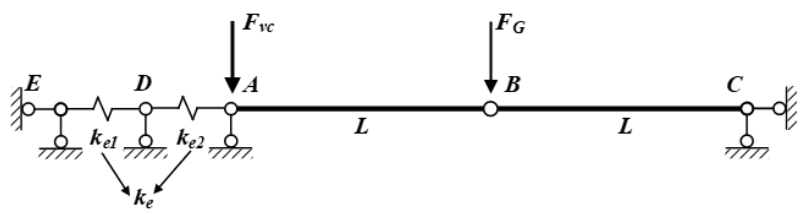

Fig. 7 The equivalent link model for catenary stage $I$

$k_{e}=\frac{1}{\frac{1}{k_{e 1}}+\frac{1}{k_{e 2}}}$

Taking the second-order effect of gravity loads into account, the axial stiffness of the springs $k_{e 1}$ and $k_{e 2}$ are given by:

$k_{e i}=\varphi_{c i} \frac{12 i_{c i}}{H_{1}^{2}}-\frac{0.5 F_{G}+F_{v c}}{H_{1}}(i=1,2)$

$F_{v c}=0.5\left(P+F_{y}\right)$

where $F_{v c}$ is the total vertical loads suffered by the column top at the base-storey; $P$ is the gravity loads from upper storeys; $i_{c i}$ is the linear stiffness of the column at the base-storey. The first item on the right of Eq. 7 represents the equivalent lateral stiffness of the column at the base-storey (shown in Fig. 8 (a)). The second item indicates the detrimental influence of the second-order effect due to gravity loads on the lateral stiffness of the column. $\varphi_{c i}$ is the reduction factor of the equivalent lateral stiffness for the column at the base-storey considering that the columns at upper storeys fail to fully restrain the column top at the basestorey (shown in Fig. 8 (b)). For regular frames with same height at each storey, the value of $\varphi_{c i}$ can be designated as 0.4 .

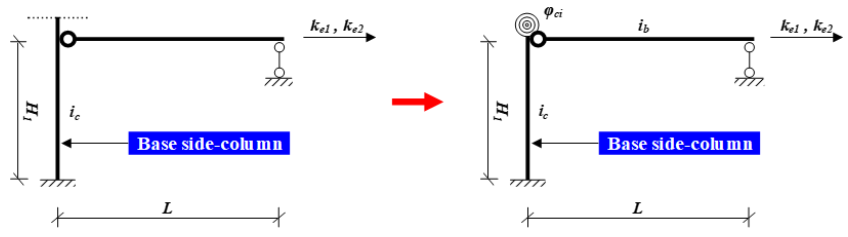

(a) Restraints of the column at base-storey

(b) The reduction factor $\varphi_{c i}$

Fig. 8 Model simplification for $k_{e l}$ and $k_{e 2}$

3.2.2. The relationship between $F_{G}$ and $\delta$

Fig. 9 gives the deformation configuration of the equivalent link model during the catenary stage $I . \Delta$ is the total lateral displacement of the equivalent spring; $\theta$ is the chord rotation of the beam at the base-story; $\delta$ is the vertical displacement at the column-removal location.

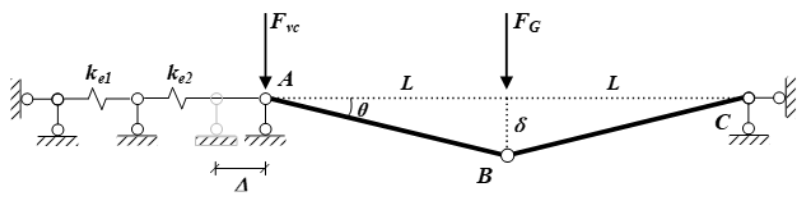

Fig. 9 Deformation configuration of the equivalent link model during catenary stage $I$
According to the deformation compatibility, the axial elongation of the beams at the base-storey is given by:

$\frac{2 L-\Delta}{2 \cos \theta}=\frac{F_{G} L}{2 E A \sin \theta}+L$

where $E$ and $A$ are the elastic modulus and section area of the beam, respectively. Based on the force equilibrium at the beam end A, the tensile force in the spring equals to the horizontal component of that in the beam, which is given by:

$$
k_{e} \Delta=\frac{F_{G}}{2 \tan \theta}
$$

Substituting Eq. 9 into Eq. 10, yielding:

$\tan \theta-\sin \theta=\frac{F_{G}}{2 E A}+\frac{F_{G}}{4 L k_{e}}$

The relationship between $\Delta$ and $\delta$ is given by:

$$
\delta=\frac{2 L-\Delta}{2} \tan \theta+H_{1}\left(1-\sqrt{\frac{H_{1}^{2}}{H_{1}^{2}+\Delta^{2}}}\right)
$$

In Eq. 12, the first item on the right indicates the vertical displacement at the column-removal location due to the chord rotation of the steel beam. The second item represents the effect of rotation of the column at the base-storey on the vertical displacement. For a given $F_{G}$, the rotation $\theta$ and lateral displacement $\Delta$ of the beam can be determined by Eq. 11 and Eq. 10, respectively. The vertical displacement $\delta$ at the column-removal location can hence be calculated by Eq 12. The total resistance of the frame $F_{c}$ is given by:

$$
F_{c}=F_{G}+\lambda_{a} \cdot F_{y}
$$

where $\lambda_{a}$ denotes the detrimental effect of the tensile force on the sectional plastic moment of the steel beam at the base-storey, which is given by [27]:

$\lambda_{a}=\frac{F_{p}-N}{F_{p}}$

where $F_{p}$ is the tensile yielding capacity of the beam section; $N$ is the tensile force in the beam.

\subsection{Catenary stage II}

In catenary stage $I I$, the resistance mechanism in the column at the basestorey is different from that in catenary stage $I$ considering that the plastic hinge occurs at the column bottom due to the increasing lateral displacement of it. As shown in Fig. 10, a modified link model is proposed wherein the plastic hinge occurring at the column bottom is considered. Similarly, the effective lateral stiffness of the side columns $k_{e}^{\prime}$ is given by:

$$
k_{e}^{\prime}=\frac{1}{\frac{1}{k_{e 1}^{\prime}}+\frac{1}{k_{e 2}^{\prime}}}
$$

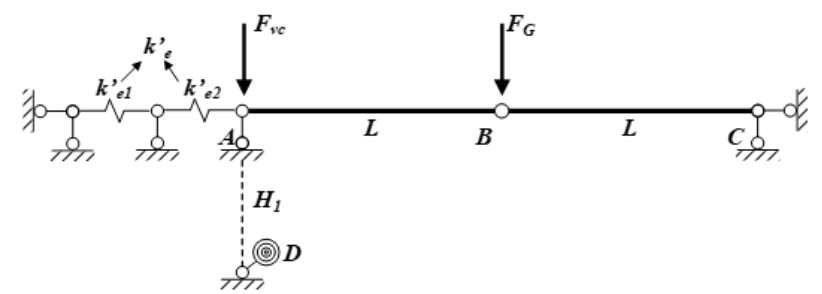

Fig. 10 The equivalent link model for catenary stage $I I$ 
where $k_{e l}^{\prime}$ and $k_{e 2}^{\prime}$ represent the lateral stiffness of side-columns with plastic hinges at the bottom of the base-storey, wherein the second-order effect of gravity loads is considered. The plastic hinges occurring at the column bottom are simplified into perfectly-elastoplastic rotational springs located at point $D$. The rigid link $A D$ is used to transfer the resistance of the plastic hinges to point $A$, which represents the column top at the base-storey. $k_{e i}^{\prime}(i=1,2)$ is given by:

$k_{e i}^{\prime}=\varphi_{e i}^{\prime} \frac{3 i_{c i}}{H_{1}^{2}}-\frac{0.5 F_{G}+F_{v c}}{H_{1}}(i=1,2)$

where $\varphi_{c i}^{\prime}$ is the modified reduction factor of the lateral stiffness of the column at the base-storey considering the unideal restraints provides by columns in upper stories, which is shown in Fig. 11. For regular frames with same height at each storey, the value of $\varphi_{c i}$ can be designated as 0.2 .

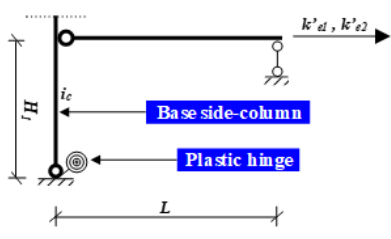

(a) Restraints of the column at base-storey

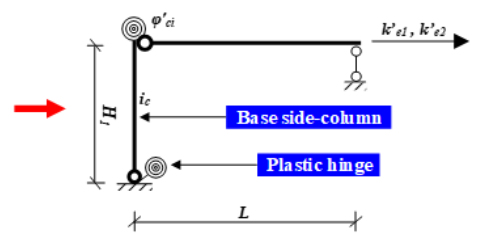

(b) The modified reduction factor $\varphi_{c i}^{\prime}$
Fig. 11 Calculation configuration of $k_{e l}^{\prime}$ and $k_{e 2}^{\prime}$ in catenary stage $I I$

Fig. 12 shows the deformation configuration of the steel beam at the basestorey. Similarly, based on the force equilibrium condition at point A:

$k_{e}^{\prime} \Delta+\frac{M_{y c}}{H_{1}}=\frac{F_{G}}{2 \tan \theta}$

where $M_{y c}$ is the plastic bending capacity at the bottom of the steel column.

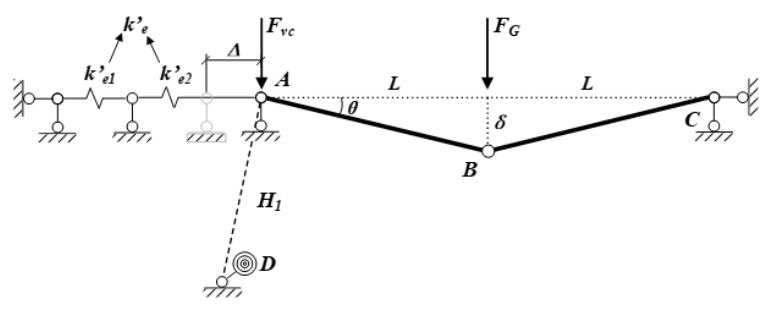

Fig. 12 Equilibrium state of the equivalent link model during catenary stage $I I$

The deformation compatibility condition of the beam at the base-storey yields that:

$\tan \theta-\sin \theta=\frac{F_{G}}{2 E A}+\frac{F_{G} H_{1}-2 M_{y c} \tan \theta}{4 L H_{1} k_{e}^{\prime}}$

The relationship between $\delta$ and $\Delta$ is further given by:

$\delta=\frac{2 L-\Delta}{2} \tan \theta+H_{1}\left(1-\sqrt{\frac{H_{1}^{2}}{H_{1}^{2}+\Delta_{1}^{2}}}\right)$

Similarly, for a given $F_{G}$, the rotation $\theta$ and lateral displacement $\Delta$ of the beam can be determined by Eq. 18 and Eq. 17, respectively. The vertical displacement at the column-removal location can be calculated by Eq. 19. The total resistance of the frame $F_{c}$ is determined by Eq. 13 .

3.4. Catenary stage III

At catenary stage $I I I$, plastic hinges occur at both ends of the columns at the base-storey and the whole structure approach the utilmate capacity due to the second-order effect of gravity loads.
3.4.1. The additional vertical force at failure location, $F_{F G}$

The deformation configuration of the bare steel frame at catenary stage III is shown in Fig. 13. With the increase of the lateral displacement at the beam ends $A$ and $C$, the resultant shear force in side-columns at upper stories $F_{v_{-} \text {uppeer }}$ will result in additional vertical force at point $B$, which is denoted as $F_{F G}$, which increases the axial force of the steel beam at the base-storey.

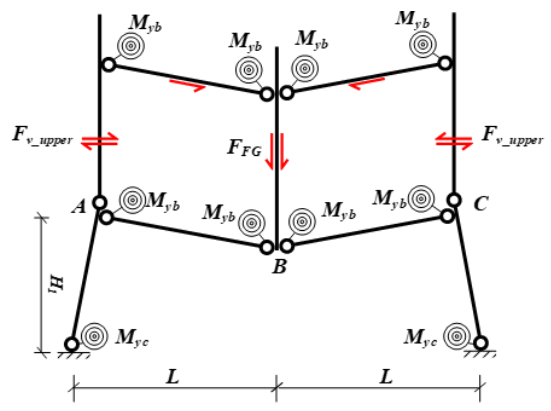

Fig. 13 The mechanism of $F_{F G}$ for catenary stage $I I$

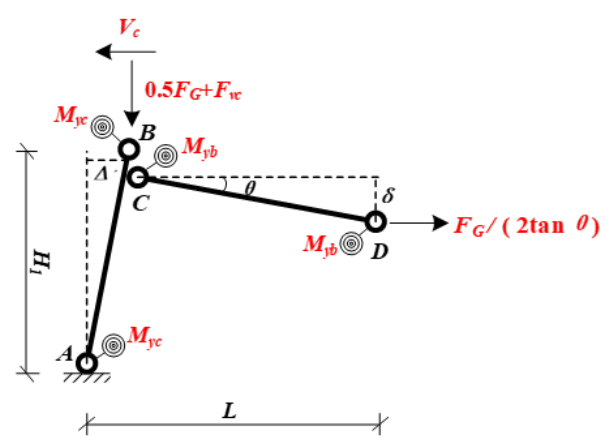

Fig. 14 Deformation configuration of the link model for catenary stage III (half model)

The determination of $F_{v \_u p p e r}$ is given by:

$F_{v_{-} u p p e r} \approx \varphi_{m y c} \frac{M_{y c}}{H_{1}}$

where $\varphi_{m y c}$ is the equivalent factor considering the influence of the frame height, whose value is designated as 0.7 for the regular bare frame structures with same storey height. Therefore, $F_{F G}$ is determined as:

$F_{F G}=2 F_{v_{-} \text {upper }} \tan \theta$

\subsubsection{The relationship between $F_{G}$ and $\delta$}

Fig. 14 shows the deformation configuration of the equivalent link halfmodel for the steel beam at the base-storey. $V_{c}$ is the shear force in columns at upper storeys. $M_{y c}$ and $M_{y b}$ are the plastic bending capacities at both ends of the column and beam, respectively. $\Delta$ ' is the lateral displacement of the column top on single side at base-storey, corresponding to the point B in Fig. 14. Based on the deformation compatibility condition:

$\frac{L-\Delta^{\prime}}{\cos \theta}=L+\frac{L}{2 E A \sin \theta}\left(F_{G}+F_{F G}\right)$

The moment-equilibrium condition about point $B$ yields:

$2 M_{y c}-M_{y b}+V_{c} \cdot H_{1}=H_{1} \cdot \frac{F_{G}+F_{F G}}{2 \tan \theta}+\left(0.5 F_{G}+F_{v c}\right) \cdot \Delta^{\prime}$

The value of $V_{c}$ can be calculated as:

$V_{c}=\varphi_{c}^{\prime \prime} \frac{M_{y c}}{H_{1}}$ 
where $\varphi{ }^{\prime \prime}{ }_{c}$ is the shear force reduction factor, taking the influence of the sidecolumns in upper stories into account, the value of which is given by 1.50 for regular structures with same storey-height. From Eq. 22 Eq. 24, the relationship between $\theta$ and $F_{G}$ can be obtained:

$\tan \theta-\sin \theta=\frac{F_{G}+F_{F G}}{2 E A}+\frac{2 \tan \theta\left(2 M_{y c}-M_{y b}+V_{c} \cdot H_{1}\right)-\left(F_{G}+F_{F G}\right) H_{1}}{2 L\left(0.5 F_{G}+F_{v c}\right)}$

Furthermore, the relationship between $\Delta$ ' and $\left(\theta, F_{G}\right)$ during catenary stage III is given in Eq. 26 and the relationship between $\delta$ and $\Delta^{\prime}$ is given in Eq. 27.

$\Delta^{\prime}=\frac{2 \tan \theta \cdot\left(2 M_{y c}-M_{y b}+V \cdot H_{1}\right)-\left(F_{G}+F_{F G}\right) H_{1}}{2 \tan \theta \cdot\left(0.5 F_{G}+F_{v c}\right)}$

$\delta=\left(L-\Delta^{\prime}\right) \cdot \tan \theta+H_{1}\left(1-\sqrt{\frac{H_{1}^{2}}{H_{1}^{2}+\Delta^{\prime 2}}}\right)$

For a given $F_{G}$, the rotation $\theta$ and lateral displacement $\Delta^{\prime}$ of the beam can be determined by Eq. 25 and Eq. 26, respectively. The vertical displacement at the column-removal location can be calculated by Eq. 27. The structure resistance $F_{c}$ is given by Eq. 13 .

\subsection{Resistance-displacement curve}

Fig. 2 shows the determinations of the resistance-displacement relationship of the bare steel frame due to a middle column loss ( $F-D$ curve). At the end of the elastic stage (Point $A$ ), the resistance of the frame is determined by Eq. 4 Eq. 5. Point $B$ is obtained by intersecting the resistance-displacement curves for catenary stages $I$ and $I I$. Similarly, the intersection of the resistancedisplacement curves for catenary stages $I I$ and $I I I$ is defined as point C. Point T corresponds to the ultimate state of the frame, wherein Eq. 25 Eq. 27 fail to have solutions. In practical engineering, other instances such as the fracture of frame beams, the failure of beam-column joints or local buckling of column components, will bring the final collapse ahead of time and decrease the capacity of bare steel frame structure, which are not to be discussed in this paper.

\section{Analytical method of collapse resistance for braced steel framed- structures}

The resistance-displacement relationships for bare and braced steel frames are the same for elastic stage and catenary stage $I$, while due to the restraints provided by the bracing system, the resistance-displacement relationships for the two structural systems are significantly different at catenary stages II and III.

\subsection{Catenary stage II for the braced steel frame}

\subsubsection{The equivalent link model}

Fig. 15 shows the equivalent link model of beams at the base-storey for the braced frame. In Fig. 16, spring with axial stiffness $k_{b e l}$ indicates the lateral restraint from side columns away from the bracing systems. Spring with axial stiffness $k_{b e 2}$ represents the lateral restraint from the bracing systems together with the side columns adjacent to the bracing system. The second-order effect of gravity loads is accounted for by rigid link DE. Due to the limited deformation, the columns close to the bracing systems are assumed to remain in elastic state.

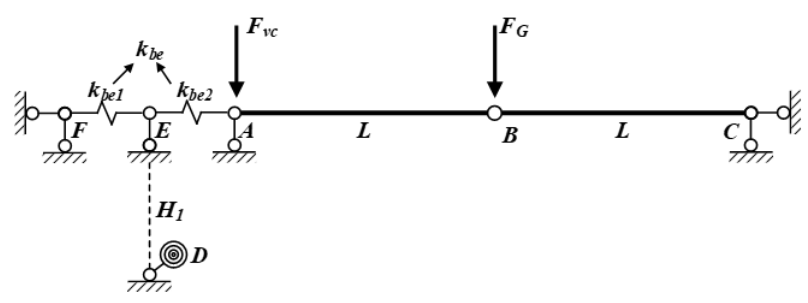

Fig. 15 The equivalent link model for braced frame structures during catenary stage $I I$

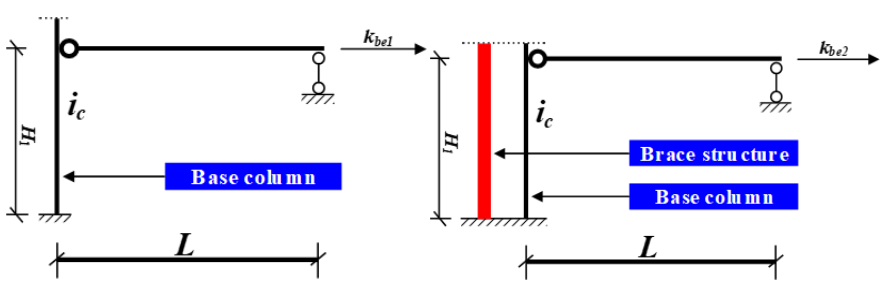

(a) $\boldsymbol{k}_{b e 1}$

(b) $k_{b e 2}$

Fig. 16 The configuration of $k_{b e l}$ and $k_{b e 2}$

The calculation method of $k_{b e l}, k_{b e 2}$ is given by:

$k_{b e 1}=k_{e 1}^{\prime}$

$k_{b e 2} \approx k_{e 2}+\varphi_{c i} \frac{12 i_{b r}}{H_{1}^{2}}$

where $\varphi_{c i}$ is the reduction factor of the equivalent lateral stiffness in Eq. 7, $i_{b r}$ is the linear stiffness of the bracing systems at the base-storey.

\subsubsection{The displacement-resistance curve during catenary stage II}

The deformation configuration of the equivalent link model for the braced frame during catenary stage $I I$ is shown in Fig. 17. Similarly, based on the deformation compatibility of the beam $\mathrm{AB}$ and $\mathrm{BC}$ and force equilibrium condition at the beam end $\mathrm{A}$, the following equations can be derived:

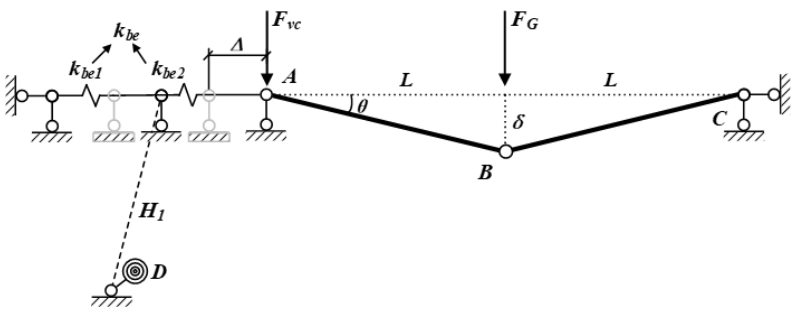

Fig. 17 The deformation configuration of equivalent link model of brace structures

$\frac{2 L-\Delta}{2 \cos \theta}=\frac{F_{G} L}{2 E A \sin \theta}+L$

$\Delta=\frac{F_{G}}{2 \tan \theta k_{b e 2}}+\left(\frac{F_{G}}{2 \tan \theta}-\frac{M_{y c}}{H_{1}}\right) / k_{b e 1}$

Yielding that:

$\delta=\frac{2 L-\Delta}{2} \tan \theta+H_{1}\left(1-\sqrt{\frac{H_{1}^{2}}{H_{1}^{2}+\Delta^{2}}}\right)$

For a given $F_{G}$, the chord rotation $\theta$ of the beam can be determined by substituting Eq. 30 into Eq. 31. The vertical displacement at the columnremoval location can be calculated by Eq. 32. The total resistance of the frame $F_{c}$ is determined by Eq. 13 .

\subsection{Catenary stage III}

During the catenary stage $I I I$, the plastic hinges occur at both ends of the side column away from the bracing systems. The instability of this column indicates the ultimate limit state of the frame. Fig. 18 shows the deformation configuration of the braced frame at the first-storey during catenary stage III. $\Delta_{b 1}$ and $\Delta_{b 2}$ represent the lateral displacement of the column top away from and close to the bracing system at the base-storey, respectively. The mechanism against collapse of the braced frame at this stage is shown in Fig. 19. $F_{v_{-} \text {upperl }}$ and $F_{v_{u} \text { upper } 2}$ represent the shear force in side columns from upper storeys. For simplification, the chord rotation of beam $\mathrm{CD}$ is assumed to be the same as that 
of beam DE. Considering that the lateral stiffness of bracing systems is great enough so that the shear force in the adjacent columns $F_{v_{\nu} \text { upper } 2}$ can be ignored. $F_{v_{\perp} \text { upper } 1}$ is given by:

$$
F_{v_{-} u p p e r 1} \approx \varphi_{m y c} \frac{M_{y c}}{H_{1}}
$$

where $\varphi_{m y c}$ is explained in Eq. 20. The additional vertical force at the columnremoval location $F_{F G}$ is calculated as:

$F_{F G} \approx F_{v_{-} \text {upper } 1} \tan \theta$

Based on the moment-equilibrium condition of column $\mathrm{AB}$ and deformation compatibility condition of beam CD (in Fig. 18):

$2 M_{y c}-M_{y b}+V_{b c 1} \cdot H_{1}=H_{1} \cdot \frac{F_{G}+F_{F G}}{2 \tan \theta}+\left(0.5 F_{G}+F_{v c}\right) \cdot \Delta_{b 1}$

$\frac{2 L-\Delta_{b 1}-\Delta_{b 2}}{2 \cos \theta} \approx L+\frac{F_{G}+F_{F G}}{2 E A \sin \theta} L$

$\Delta_{b 2}$ can be determined by linear-elastic principle:

$\Delta_{b 2}=\frac{F_{G}}{2 k_{e 2} \tan \theta}$

$V_{b c l}$ is given by:

$V_{b c 1}=\varphi_{c}^{\prime \prime} \frac{M_{y c}}{H_{1}}$

where $\varphi{ }^{\prime}{ }_{c}$ is explained in Eq. 24. According to Eq. 35 Eq. 38, the relationship between $F_{G}$ and $\theta$ can be figured out. Meanwhile, $\Delta_{b l}$ and $\delta$ is given in Eq. 39 and Eq. 40 , respectively.

$\Delta_{b 1}=\frac{2 \tan \theta \cdot\left(2 M_{y c}-M_{y b}+V_{b c 1} \cdot H_{1}\right)-\left(F_{G}+F_{F G}\right) H_{1}}{2 \tan \theta \cdot\left(0.5 F_{G}+F_{v c}\right)}$

$\delta=\frac{2 L-\Delta_{b 1}-\Delta_{b 2}}{2} \cdot \tan \theta+H_{1}\left(1-\sqrt{\frac{H_{1}^{2}}{H_{1}^{2}+\Delta_{b 1}^{2}}}\right)$

The determination of the resistance-displacement relationship for the braced frame is the same with that for the bare frame. The details are introduced in Section 3.5.

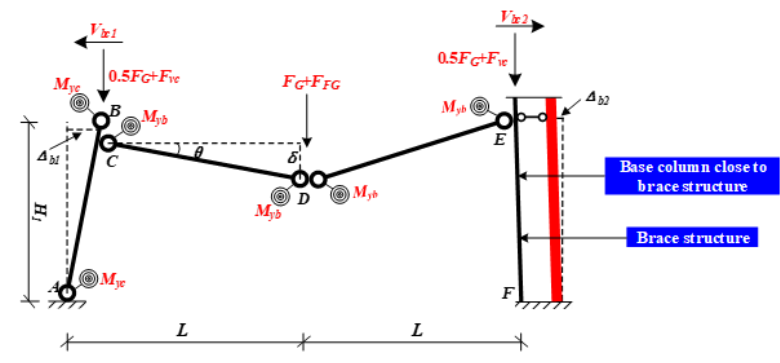

Fig. 18 The deformation configuration of the braced frame during catenary stage III

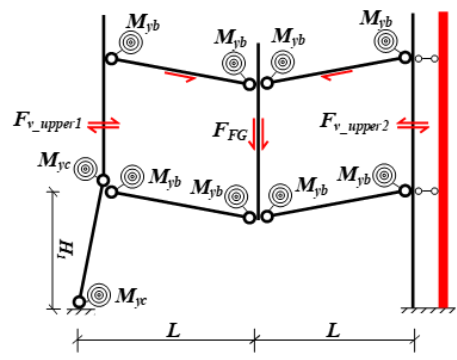

Fig. 19 The mechanism of the braced frame during catenary stage $I I I$

It should be noted that the beam at each storey is assumed to suffer from the same uniformly distributed load herein. In practical engineering, the uniformly distributed load may be different at each storey. However, considering that the collapse state of the frame is controlled by the stability of the columns at the first storey and only the total gravity load from upper storeys is required to quantify the second-order effect, the proposed method is still applicable.

\section{Numerical analysis}

The accuracy of the proposed analytical method is verified by numerical analyses by using the finite elment software ABAQUS. Parametric studies are launched to further investigate the collapse mechanism of the steel frame in the event of a middle column loss.

\subsection{Finite element models}

As shown in Fig. 20, the numerical bare and braced reference frames are six-storey with a span of $6 \mathrm{~m}$ and storey height of $3.6 \mathrm{~m}$. The section dimensions of the beams and columns in the frames are correspondingly identical. The steel beams and columns are simulated by two-node beam elements (B21). For the braced frame, the "Coupling" Command is employed to connect the bracing system and the main frame. The mesh size of the columns and beams are assigned as 1/4 of their section height. The bi-linear stress-strain relationship with kinematic hardening is employed to model the characteristics of steel. The yielding stress of the steel is $345 \mathrm{MPa}$ and the post-yielding stiffness is $6.18 \times 10^{3} \mathrm{MPa}$. The bottoms of the columns are fully restrained. The linear distributed load applied on the beams is $20 \mathrm{kN} / \mathrm{m}$. Displacement-controlled loading is applied at the column-removal location to obtain the resistancedisplacement relationship of the frame. The target vertical displacement is assigned as $3.0 \mathrm{~m}$ at the column-removal location. The general static procedure is used and the geometric nonlinearity is considered for large deflections. It should be noted that the effect of the initial geometric imperfection of the column is not considered. This is because the second-order effect of the gravity load is mainly induced by the lateral displacement at the top of the column.

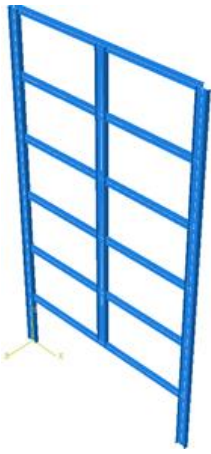

(a) Bare steel frame

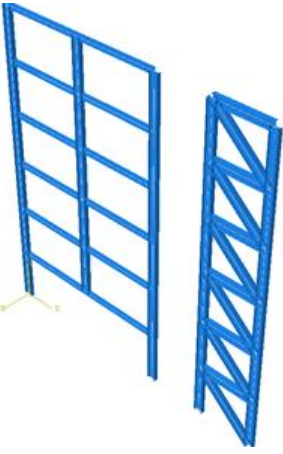

(b) Braced steel frame
Fig. 20 Finite element models of the two structural systems

\subsection{Parametric study scheme}

In the parametric studies, the target structural parameters are the span of the beam, number of storey and the relative stiffness ratio of beam to column in the frame. The details of the parameters for the bare and braced frames are shown in Table 2 and Table 3 , respectively. 
Table 2

Details of the parametric study for the bare frames

\begin{tabular}{|c|c|c|c|c|c|}
\hline No. of bare frame model & Number of storey & Span & Stiffness ratio & Beam section & Column section \\
\hline FS6B6R $1^{*}$ & 6 & 6 & 0.17 & $\mathrm{H} 400 \times 200 \times 14 \times 10$ & \multirow{7}{*}{$\mathrm{H} 600 \times 300 \times 14 \times 10$} \\
\hline FS6B7R1 & 6 & 7 & 0.17 & $\mathrm{H} 430 \times 200 \times 14 \times 10$ & \\
\hline FS6B8R1 & 6 & 8 & 0.17 & $\mathrm{H} 440 \times 220 \times 14 \times 10$ & \\
\hline FS4B6R1 & 4 & 6 & 0.17 & $\mathrm{H} 400 \times 200 \times 14 \times 10$ & \\
\hline FS8B6R1 & 8 & 6 & 0.17 & $\mathrm{H} 400 \times 200 \times 14 \times 10$ & \\
\hline FS6B6R2 & 6 & 6 & 0.34 & $\mathrm{H} 500 \times 250 \times 14 \times 10$ & \\
\hline FS6B6R3 & 6 & 6 & 0.60 & $\mathrm{H} 600 \times 300 \times 14 \times 10$ & \\
\hline
\end{tabular}

Table 3

Details of the parametric study for the braced frames

\begin{tabular}{|c|c|c|c|c|c|c|}
\hline No. of bare frame model & Number of storey & Span & Stiffness ratio & Beam section & Column section & Brace components \\
\hline BS6B6R $1^{* * *}$ & 6 & 6 & 0.17 & $\mathrm{H} 400 \times 200 \times 14 \times 10$ & \multirow{7}{*}{$\mathrm{H} 600 \times 300 \times 14 \times 10$} & \multirow{7}{*}{$\mathrm{H} 600 \times 300 \times 14 \times 10$} \\
\hline BS6B7R1 & 6 & 7 & 0.17 & $\mathrm{H} 430 \times 200 \times 14 \times 10$ & & \\
\hline BS6B8R1 & 6 & 8 & 0.17 & $\mathrm{H} 440 \times 220 \times 14 \times 10$ & & \\
\hline BS4B6R1 & 4 & 6 & 0.17 & $\mathrm{H} 400 \times 200 \times 14 \times 10$ & & \\
\hline BS8B6R1 & 8 & 6 & 0.17 & $\mathrm{H} 400 \times 200 \times 14 \times 10$ & & \\
\hline BS6B6R2 & 6 & 6 & 0.34 & H $500 \times 250 \times 14 \times 10$ & & \\
\hline BS6B6R3 & 6 & 6 & 0.60 & $\mathrm{H} 600 \times 300 \times 14 \times 10$ & & \\
\hline
\end{tabular}

\subsection{Verification of the analytical method}

\subsubsection{The collapse mechanism}

Fig. 21 presents the deformation configuration of bare and braced reference frames (FS6B6R1 and BS6B6R1) when the vertical displacement at the middlecolumn-loss location reaches $3.0 \mathrm{~m}$. Fig. 22 shows the comparisons between the resistance-displacement relationships for the bare and braced frames. The findings are summarized as follows:

a. A reasonable beam-to-column stiffness ratio ensures that plastic hinges occur at both ends of the steel beams, wherein the catenary action can effectively develop. Little damage is found in the steel columns from upper storeys.

b. The bracing systems provides great lateral restraints to the adjacent columns and those columns remain in elastic even at large deflections. However, for the bare frame, plastic hinges occur in the column ends at both sides due to its symmetric deformation.

c. The displacement-resistance relationships of the two frames can be divided into four stages. The elastic stage and catenary stage $I$ for the curves are identical for bare and braced frames. This further verifies the rationality of the assumption in the analytical method.

d. The bracing systems leads to a damage concentration at the column away from the bracing systems and thus reduce the ultimate bearing capacity of the frame with certain extent. Moreover, the failure displacement at the column-removal location of the braced frame is $36.5 \%$ smaller than that of the bare frame and the ultimate bearing capacity of the braced frame is $5.3 \%$ lower than that of the bare frame.

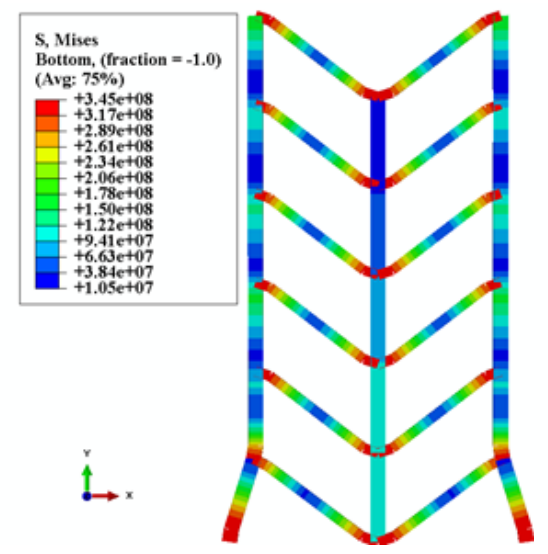

(a) FS6B6R1

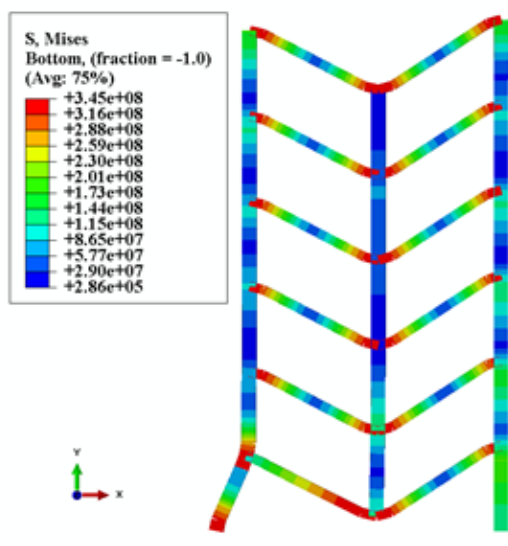

(b) BS6B6R1

Fig. 21 The deformation of bare and braced reference frames due to a middle column loss 


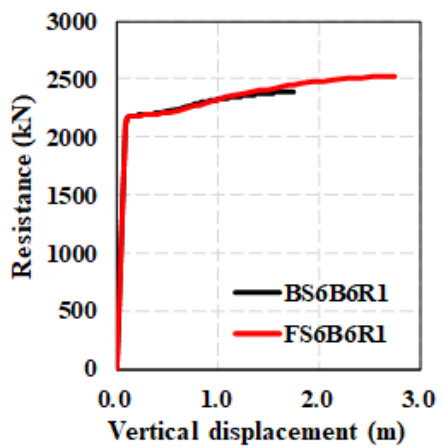

Fig. 22 The displacement-resistance curve comparison

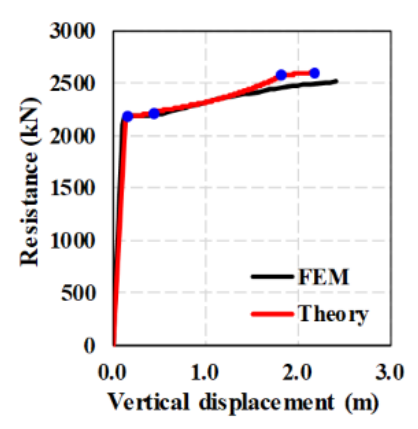

(a) FS6B6R1

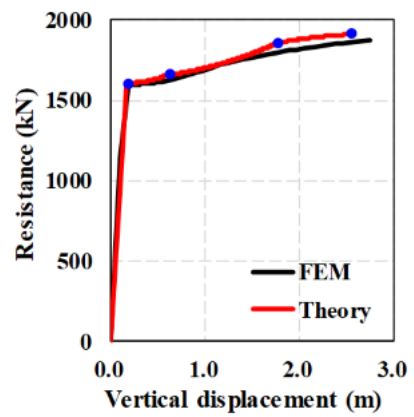

(e) FS6B8R1

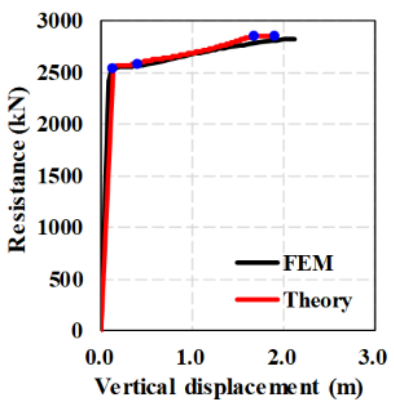

(i) FS8B6R1

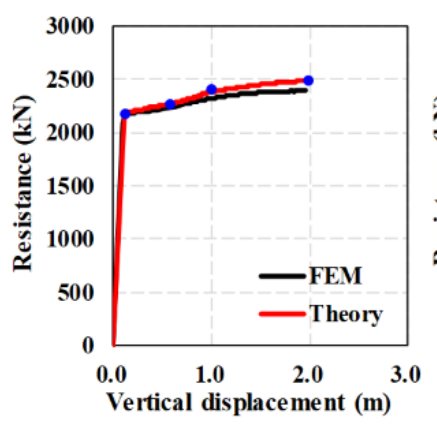

(b) BS6B6R1

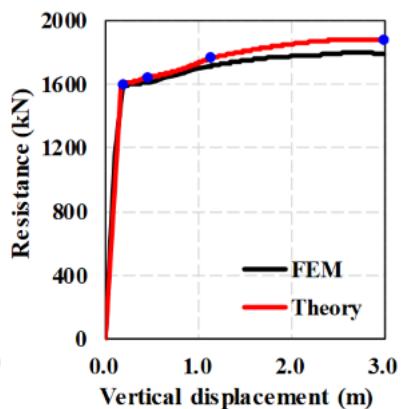

(f) BS6B8R1

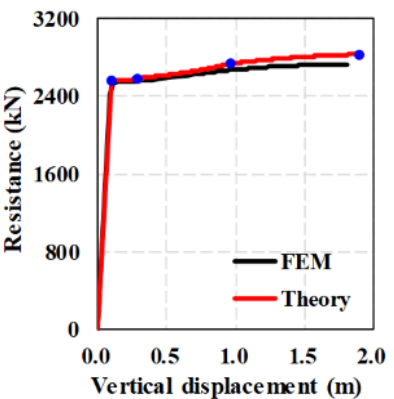

(j) BS8B6R1

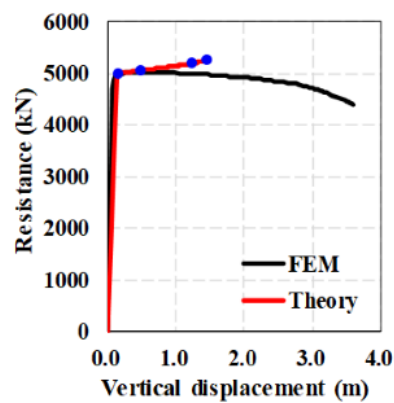

(m) FS6B6R3

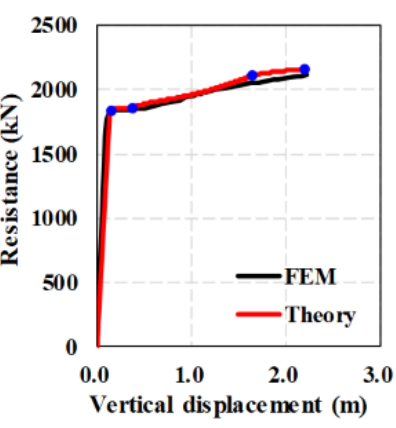

(c) FS6B7R1

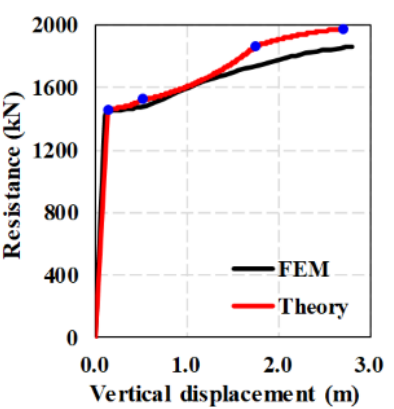

(g) FS4B6R1

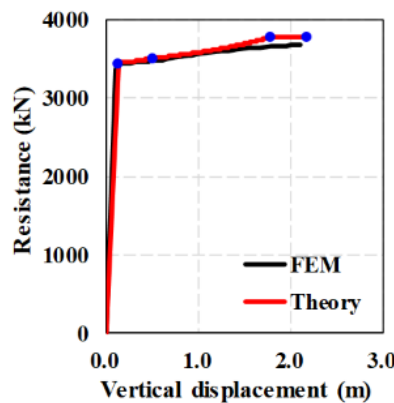

(k) FS6B6R2

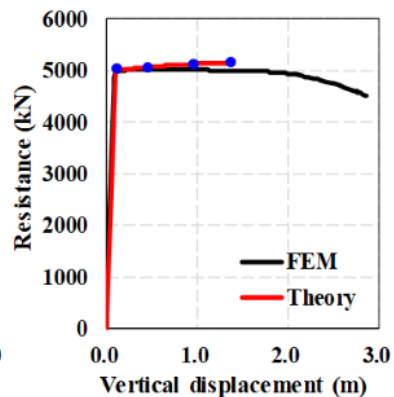

(n) BS6B6R3

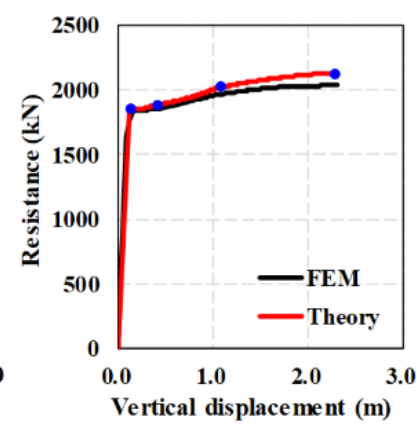

(d) BS6B7R1

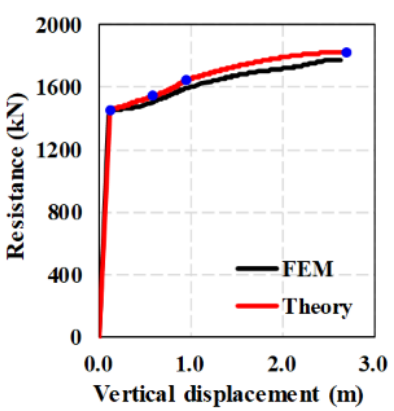

(h) BS4B6R1

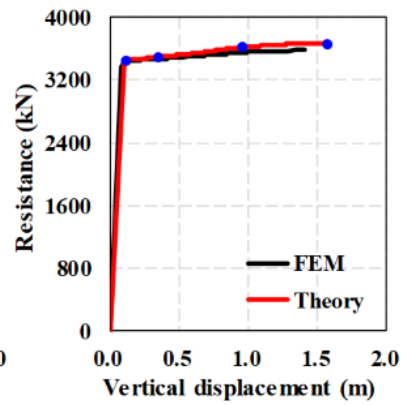

(l) BS6B6R2

Fig. 23 Comparisons on the numerical and analytical resistance-displacement curves of the studied frames 
Table 4

The results of pushdown analysis for the frames with and without bracing system

\begin{tabular}{|c|c|c|c|c|c|c|c|c|}
\hline Case & $F_{y_{-} F E M}(\mathrm{kN})$ & $F_{y_{-} \text {theory }}(\mathrm{kN})$ & $F_{C_{-} F E M}(\mathrm{kN})$ & $F_{c_{-} \text {theory }}(\mathrm{kN})$ & $\Delta_{v_{-} F E M}(\mathrm{~m})$ & $\Delta_{v_{-} \text {theory }}(\mathrm{m})$ & {$\left[F_{c}\right]$} & {$\left[\Delta_{v}\right]$} \\
\hline FS6B6R1 & 2182 & 2185 & 2511 & 2603 & 2.409 & 2.165 & $3.5 \%$ & $-11.3 \%$ \\
\hline FS6B7R1 & 1846 & 1847 & 2111 & 2160 & 2.233 & 2.219 & $2.3 \%$ & $-0.6 \%$ \\
\hline FS6B8R1 & 1605 & 1606 & 1869 & 1911 & 2.738 & 2.535 & $2.2 \%$ & $-8.0 \%$ \\
\hline FS4B6R1 & 1464 & 1465 & 1863 & 1973 & 2.789 & 2.671 & $5.6 \%$ & $-4.4 \%$ \\
\hline FS8B6R1 & 2559 & 2560 & 2827 & 2857 & 2.120 & 1.900 & $1.0 \%$ & $-11.6 \%$ \\
\hline FS6B6R2 & 3461 & 3463 & 3682 & 3789 & 2.097 & 2.160 & $2.8 \%$ & $2.9 \%$ \\
\hline FS6B6R3 & 5014 & 5015 & 5021 & 5244 & 3.600 & 1.432 & $4.3 \%$ & $-151.4 \%$ \\
\hline BS6B6R1 & 2184 & 2194 & 2389 & 2486 & 1.961 & 1.953 & $3.9 \%$ & $-0.4 \%$ \\
\hline BS6B7R1 & 1846 & 1846 & 2041 & 2131 & 2.305 & 2.271 & $4.2 \%$ & $-1.5 \%$ \\
\hline BS6B8R1 & 1605 & 1604 & 1803 & 1882 & 2.977 & 2.986 & $4.2 \%$ & $0.3 \%$ \\
\hline BS4B6R1 & 1464 & 1463 & 1773 & 1825 & 2.616 & 2.661 & $2.9 \%$ & $1.7 \%$ \\
\hline BS8B6R1 & 2559 & 2558 & 2723 & 2831 & 1.807 & 1.876 & $3.8 \%$ & $3.7 \%$ \\
\hline BS6B6R2 & 3461 & 3461 & 3579 & 3677 & 1.411 & 1.562 & $2.7 \%$ & $9.7 \%$ \\
\hline BS6B6R3 & 5014 & 5011 & 5024 & 5147 & 2.872 & 1.355 & $2.4 \%$ & $-112.0 \%$ \\
\hline \multicolumn{9}{|l|}{ Notes: } \\
\hline \multicolumn{9}{|c|}{ (1) $F_{y_{-} F E M}$ represents the numerical yielding capacity of the structures } \\
\hline \multicolumn{9}{|c|}{ (2) $F_{y_{-} \text {theory }}$ represents the analytical yielding capacity of the structures } \\
\hline \multicolumn{9}{|c|}{ (3) $F_{C_{-} F E M}$ represents the numerical ultimate capacity of the structures } \\
\hline \multicolumn{9}{|c|}{ (4) $F_{c_{-} \text {theory }}$ represents the analytical ultimate capacity of the structures } \\
\hline \multicolumn{9}{|c|}{ (5) $\Delta_{V_{-} F E M}$ represents the numerical failure vertical displacement at the column-removal location } \\
\hline \multicolumn{9}{|c|}{ (6) $\Delta_{c_{-} \text {theory }}$ represents theanalytical failure vertical displacement at the column-removal location } \\
\hline \multicolumn{9}{|c|}{ (7) $\left[F_{c}\right]$ represents the relative difference of the ultimate capacity between the numerical and analytical results } \\
\hline (8) $\left[\Delta_{v}\right]$ represe & elative differe & the failure disp & ent between $n$ & and analy & & & & \\
\hline
\end{tabular}

\subsubsection{Verifications of the analytical method}

The comparisons of the numerical and analytical resistance-displacement relationships for the bare and braced frames are shown in Fig. 23. The collapse of the frame is due to the destabilizing of the column at the first storey for Fig. 23(a)- Fig. 23(1). To further quantify the performance of the analytical method, the comparisons of the yielding capacity, ultimate capacity, and ultimate displacement of the frames with and without bracing system are given in Table 4. The findings can be drawn as follows:

a. The four-stage resistance-displacement relationship can capture the main collapse mechanisms during the column-removal process for the bare and braced steel frames. The yielding capacity, the ultimate capacity, the postyielding stiffness and the ultimate displacement of the frame can be reasonably predicted by the analytical method with acceptable errors.

b. For the bare and braced steel frames, the analytical resistance-displacement relationships during the elastic stage and catenary stage $I$ are almost identical with those from the numerical analyses. While the analytical method tends to slightly overestimate the resistance of the frame at catenary stage II and III. This is because the plastic regions are assumed to concentrate at the ends of the beams and columns in the analytical method.
Moreover, the remaining regions of the beams and columns are assumed to be in elastic state.

c. The ultimate capacity of the frames increase when the number of the storey increases. A smaller span and larger section dimension of the beam ensure a higher ultimate capacity of the frame.

d. In Table 4, the ultimate capacity of FS6B6R3 and BS6B6R3 obtained by analytical method are much lower than that obtained by numerical analysis. This is because the section dimension of the beams is relatively great and the plastic hinges firstly develop at the middle of columns, rather than the column ends at the base-storey. Fig. 24 gives the collapse configuration, wherein the final failure mode of the frame is mainly governed by the component buckling, rather than the instability of the columns, which is beyond discussion in this paper.

It should be noted that the collapse resistance of the steel frame is studied based on a static column-removal scenario herein. The dynamic amplification effect is not considered. In real cases, however, the methodology in this manuscript can be easily extended to account for the dynamic amplification effect based on the energy conservation principle [28-30].

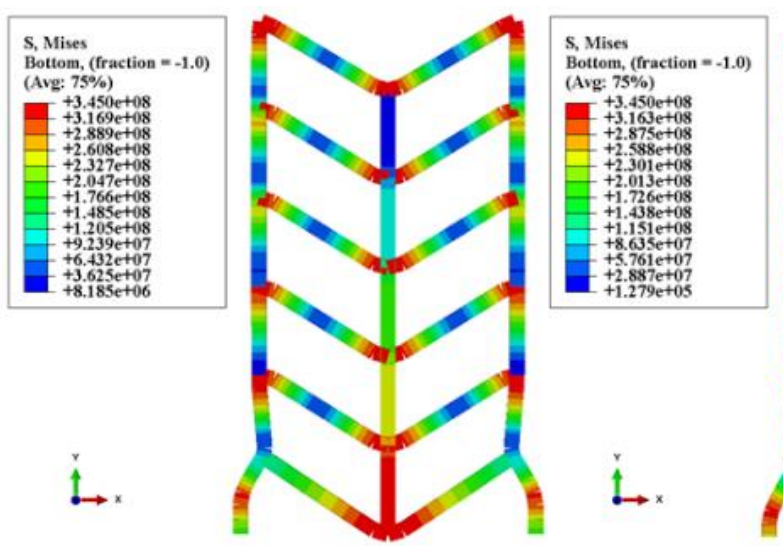

(a) FS6B6R3
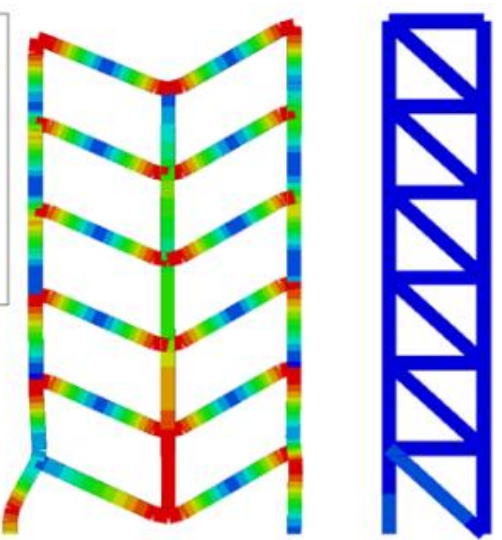

(b) BS6B6R3

Fig. 24 The progressive collapse due to the component buckling of the columns 


\section{Conclusion}

This paper analytically studies the collapse resistance of bare and braced steel frames due to a middle column loss. A four-stage resistance-displacement relationships are proposed for both the bare and braced steel frame during the column-removal process. The accuracy of the analytical method is verified against numerical analyses. The following conclusions can be drawn:

(1) The bracing system enhances the lateral stiffness of the frame with certain extents, however, due to a damage concentration on the columns away from it, it reduces the collapse resistance of the frame at large deflections and leads to smaller failure displacement of the frame due to the loss of stability of the column.

(2) The yielding capacity, ultimate capacity, post-yielding stiffness and ultimate displacement of the frame can be reasonably predicted by the analytical method with acceptable errors.

(3) At large deflections, the catenary action in steel beams enhances the

\section{References}

[1] Office of the Deputy Minister. The building regulations 2000. London (UK), 2004

[2] Pearson C, Delatte N. Ronan point apartment tower collapse and its effect on building codes. Journal of Performance of Constructed Facilities 2005; 19(2): 172-177.

[3] Corley WG, Sr PFM, Sozen MA, Thornton CH. The Oklahoma City Bombing Summary and Recommendations for Multihazard Mitigation. Journal of Performance of Constructed Facilities 1998; 12(3): 100-112.

[4] Bazant ZP, Zhou Y. Why did the World Trade Center collapse? - Simple analysis. Journal of Engineering Mechanics; 128(1): 2-6.

[5] ASCE. Minimum design loads for buildings and other structures. Reston, 2005.

[6] GSA. Progressive collapse analysis and design guidelines for new federal office buildings and major modernization projects. Washington, DC, 2013.

[7] DoD. Unified facilities criteria: design of structures to resist progressive collapse. Washington, DC, 2010.

[8]Li G, Zhang J, Jiang J. Multi-Storey Composite Framed-Structures due to Edge-Column Loss. Advanced Steel Construction 2020; 16(1): 20-29.

[9] Jiang B, Li G, Li L, Izzuddin BA. Experimental Studies on Progressive Collapse Resistance of Steel Moment Frames under Localized Furnace Loading. Journal of Structural Engineering 2018; 144(2): 4017190.

[10] Li HH, Zhang BY, Cai XH. Assessment of Design Requirements Against Progressive Collapse in UFC 4-023-03: Numerical Simulation. Advanced Steel Construction 2018; 14(4): 514-538.

[11] Li G, Li L, Jiang B, Lu Y. Experimental study on progressive collapse resistance of steel frames under a sudden column removal scenario. Journal of Constructional Steel Research 2018; 147: 1-15.

[12] Meng B, Li LD, Zhong WH, Hao JP, Tan Z. Enhancing collapse-resistance of steel frame joints based on folded axillary plates. Advanced Steel Construction 2021; 17(1): 84-94.

[13] Jiang B, Li G, Usmani A. Progressive collapse mechanisms investigation of planar steel moment frames under localized fire. Journal of Constructional Steel Research 2015; 115: 160-168.

[14] Li GQ, Zhang Y, Yang TC, Jiang J, Lu Y, Chen SW. Effect of Blast-Induced Column Failure Pattern on Collapse Behavior of Steel Frames. Advanced Steel Construction 2018; 14(3): 377-391.

[15] Stylianidis PM, Nethercot DA, Izzuddin BA, Elghazouli AY. Robustness assessment of frame structures using simplified beam and grillage models. Engineering Structures 2016; 115: 78-95. resistance of the frame, while the second-order effect of gravity loads impedes the increase of the resistance of the frame. During elastic stage and catenary stage $I$, no obvious difference is observed for the resistance-displacement relationship of the bare and braced frames. The bracing systems mainly influence the resistance of the frame at catenary stages II and III.

(4) The ultimate capacity of the frame mainly depends on the number of storeys, span of the beams and the beam to column stiffness ratio of the frame. A greater number of storeys, shorter span of beams and larger beam to column stiffness ratio generally ensure better performances of the frame against collapse.

\section{Acknowledgements}

The works in this paper was sponsored by the Thirteen-Five Science and Technology Support Program with grant 2016YFC0701203. It is necessary to express the sincere gratitude of the writers to the sponsors.

[16] Jiang BH, Li GQ, Izzuddin BA. Dynamic performance of axially and rotationally restrained steel columns under fire. Journal of Constructional Steel Research 2016; 122: 308-315.

[17] Gao S, Xu M, Guo L, Zhang S. Behavior Of CFST-Column To Steel-Beam Joints in the Scenario of Column Loss. Advanced Steel Construction 2019; 15(1): 47-54.

[18] Jiang J, Li G, Usmani A. Effect of Bracing Systems on Fire-Induced Progressive Collapse of Steel Structures Using OpenSees. Fire Technology 2015; 51(5): 1249-1273.

[19] Tsai M. A performance-based design approach for retrofitting regular building frames with steel braces against sudden column loss. Journal of Constructional Steel Research 2012; 77: $1-11$

[20] Eletrabi H, Marshall JD. Catenary action in steel framed buildings with buckling restrained braces. Journal of Constructional Steel Research 2015; 113: 221-233.

[21] Talebi E, Tahir MM, Zahmatkesh F, Kueh ABH, Said AM. Fire Resistance of a Damaged Building Employing Buckling Restrained Braced System. Advanced Steel Construction 2018; 14(1): $1-21$.

[22] Naji A, Ommetalab MR. Horizontal bracing to enhance progressive collapse resistance of steel moment frames. The Structural Design of Tall and Special Buildings 2019; 28(5): e1563.

[23] Asgarian B, Hashemi Rezvani F. Progressive collapse analysis of concentrically braced frames through EPCA algorithm. Journal of Constructional Steel Research 2012; 70: 127 136.

[24] Li G, Dong Z, Li H. Simplified Collapse-Prevention Evaluation for the Reserve System of Low-Ductility Steel Concentrically Braced Frames. Journal of Structural Engineering 2018 , 144(040180717):

[25] Chen J, Peng W, Ma R, He M. Strengthening of Horizontal Bracing on Progressive Collapse Resistance of Multistory Steel Moment Frame. Journal of Performance of Constructed Facilities 2012; 26(5): 720-724.

[26] Jiang J, Li G. Mitigation of Fire-Induced Progressive Collapse of Steel Framed Structures Using Bracing Systems. Advanced Steel Construction 2019; 15(2): 192-202.

[27] Izzuddin BA. A Simplified Model for Axially Restrained Beams Subject to Extreme Loading. International Journal of Steel Structures 2005; 5(5): 421-429.

[28] Izzuddin BA, Vlassis AG, Elghazouli AY, Nethercot DA. Progressive collapse of multistorey buildings due to sudden column loss -Part I: Simplified assessment framework. Engineering Structures 2008; 30: 1308-1318.

[29] Wang W, Wang JJ, Sun X, Bao Y. Slab effect of composite subassemblies under a column removal scenario. J CONSTR STEEL RES. 2017; 129: 141-155.

[30] Fu QN, Tan KH, Zhou XH, Yang B. Numerical simulations on three-dimensional composite structural systems against progressive collapse. J CONSTR STEEL RES 2017; 135: 125-136. 